\title{
Philosophiques
}

\section{Pierre Macherey, À quoi pense la littérature? Exercices de la philosophie littéraire, Presses Universitaires de France, collection Pratiques théoriques, 1990, 253 pages.}

\section{Marc Turgeon}

Volume 18, numéro 2, automne 1991

URI : https://id.erudit.org/iderudit/027161ar

DOI : https://doi.org/10.7202/027161ar

Aller au sommaire du numéro

Éditeur(s)

Société de philosophie du Québec

ISSN

0316-2923 (imprimé)

1492-1391 (numérique)

Découvrir la revue

Citer ce compte rendu

Turgeon, M. (1991). Compte rendu de [Pierre Macherey, À quoi pense la littérature? Exercices de la philosophie littéraire, Presses Universitaires de

France, collection Pratiques théoriques, 1990, 253 pages.] Philosophiques, 18(2),

182-183. https://doi.org/10.7202/027161ar d'utilisation que vous pouvez consulter en ligne.

https://apropos.erudit.org/fr/usagers/politique-dutilisation/ 
Pierre Macherey, À quoi pense la littérature? Exercices de philosophie littéraire, Presses Universitaires de France, collection Pratiques théoriques, 1990, 253 pages.

$$
\text { par Marc Turgeon }
$$

Le livre de Pierre Macherey essaie de resituer, à partir d'un certain nombre d' "études de cas", les rapports de la littérature à la philosophie. L'ouvrage comporte trois parties et discute de neuf œuvres regroupées thématiquement, si bien que les sous-titres constituent les principales entrées d'une typologie à laquelle pourraient se greffer d'autres corpus de la même famille:

I. Les chemins de l'histoire (Mme de Staël - le rôle de la culture dans la constitution d'un peuple et de son identité nationale; le lien entre représentations idéales et pratiques collectives; George Sand - l'exploration de la pensée religieuse, du thème de l'humanité et de l'universalité; Raymond Queneau - la transposition du thème hégélien de la fin de l'histoire).

II. Au fond des choses (Victor Hugo - la naissance d'une littérature des profondeurs, la découverte, au XIXe siècle de l'antithèse de la foule et du sublime; Georges Bataille - une anthropologie matérialiste centrée sur le thème de l'ignominie; Céline - la littérature du dégoût, du ressentiment et de la faute).

III. Tout doit disparaitre (Sade - la rencontre du pouvoir et de la jouissance dans le récit, nous menant à la limite de la représentation, le rien au-delà des mots; Flaubert - le réel toujours absent et qui se dérobe aux efforts de l'écrivain pour le saisir par des images; Raymond Roussel de Foucault - la littérature, non comme un leurre, un masque posé sur la folie, mais comme exploration d'un langage du vide dans lequel l'œuvre toujours absente et la folie communiquent). 
Ces exercices de philosophie littéraire ne cherchent pas, selon le mot de l'A., à nier le "cercle immémorial" de la confrontation entre littérature et philosophie pour revendiquer la primauté de l'une ou de l'autre. Ils ne cherchent pas non plus à faire l'histoire de la production de l'opposition entre littérature et philosophie, mais à donner quelques exemples, dans une perspective thématique, de la manière dont l'une et l'autre se croisent, faisant intervenir l'histoire et la philosophie comme ensemble de référence de l'analyse littéraire:

une sorte de parcours théorique conduisant de spéculations sur le devenir (" les chemins de l'histoire») à des variations spéculatives sur le thème de l'immanence ( « au fond des choses ») pour aboutir à une réflexion sur la mort (« tout doit disparaître »). Le devenir, l'immanence et la mort: à travers l'enchaînement de ces notions semble s'esquisser l'allure générale d'un message. Tout se passe comme si les oeuvres de la Littérature, au sens historique de cette expression..., donnaient chacune leur version d'un unique discours, qu' elles auraient communément en partage, et qui constituerait leur " philosophie ". Ce discours se résumerait de la manière suivante: en suivant les chemins de l'histoire, on parvient au fond des choses, jusqu'au point où tout doit disparaître (194).

Cette méthode n'est pas celle dans laquelle, comme le droit ou la religion, la littérature devient un objet pour un discours philosophique de type démonstratif qui localise des territoires et des préoccupations. La philosophie littéraire que nous propose l'A. se veut plutôt un discours de comparaison de la littérature et de la philosophie en termes de production: ce que l'une et l'autre font des ressources de l'autre et de l'une. Non l'exposé de la philosophie inconsciente des écrivains, ni une stylistique des philosophes, mais la recherche, dans les formes littéraires, de la pensée que produit la littérature: un écart, une ironie de la pensée qui n'adhère jamais, ni à l'identité, ni au concept. Un miroir brisé du réel.

Le livre de Macherey est à situer dans la foulée du travail de Foucault - plutôt que celui de Derrida - sur l'épistémologie des formes littéraires. Il accompagne ainsi le renouveau des études thématiques en France ces dernières années. Il est toutefois dommage qu'il n'ait pas su tirer profit du travail fait en ce sens par des théoriciens tels Northrop Frye ou Kenneth Burke, ou encore Ernst Jauss, qui ont exploré les ressources de la rhétorique dans la constitution de typologies de thèmes et de formes discursives (l'ironie, notamment) permettant de saisir la conjonction d'un certain nombre de préoccupations littéraires et philosophiques dans leur historicité. 